\title{
ESTUDOS TAXONÔMICOS EM DICHANTHELIUM (HITCHC. \& CHASE) GOULD (POACEAE: PANICEAE) NO SEMIÁRIDO, COM ÊNFASE NA CHAPADA DIAMANTINA, BAHIA
}

\author{
Andreza Oliveira Matos'; Reyjane Patricia de Oliveira²;
}

1. Bolsista PIBIC/CNPQ, Graduando em Licenciatura em Ciências Biológicas, Universidade Estadual de Feira de Santana, e-mail: aandreza.oliveiram@gmail.com

2. Orientador, Departamento de Ciências Biológicas, Universidade Estadual de Feira de Santana, e-mail: rpatricia@uefs.br

PALAVRAS-CHAVE: gramíneas, taxonomia, Panicum s.1.

\section{INTRODUÇÃO}

Dichanthelium (Hitchc. \& Chase) Gould é um gênero pertencente à subfamília Panicoideae, membro da tribo Paniceae (Morrone et al., 2012) e subtribo Dichanteliinae (Soreng et al 2015). Apresenta ampla distribuição desde o Canadá, na América do Norte até a Argentina (Brown \& Smith, 1975), sendo reconhecidas cerca de 26 espécies para o Brasil (Viana \& Rodrigues, 2015). De forma geral, pode ser caracterizado pelo hábito, as folhas formando mais ou menos em roseta basal; claro dimorfismo foliar, e suas espiguetas diferem pouco de Panicum L., apresentando um curto apículo no antécio superior (Aliscioni et al., 2003). É um gênero de difícil delimitação, que tem uma estreita e histórica relação com Panicum, considerado um subgênero deste durante muitas décadas, principalmente devido à diferenciação entre os espécimes dos EUA e de outras regiões das Américas (Aliscioni et al., 2003).

Dentre as espécies de Dichanthelium citadas para o Brasil, 12 tem sido referidas para a Bahia (Viana \& Rodrigues, 2015) e oito delas são registradas para a Chapada Diamantina, boa parte endêmica desta região. Porém, o conhecimento a respeito desse gênero pode ser considerado ainda muito limitado, uma vez que: a) as espécies apresentam delimitação relativamente complexa, com nomes aplicados de maneira duvidosa; b) existem muitas coleções em herbário sem identificação; c) nenhum dos taxonomistas de Poaceae do Brasil trabalha com o gênero no momento.

Assim, estudos aprofundados Dichanthelium tornam-se claramente necessários, a fim de ampliar os conhecimentos a respeito da diversidade do gênero no Brasil, tendo como ponto de partida a análise das coleções feitas nos limites do Semiárido, com ênfase na Chapada Diamantina.

\section{METODOLOGIA}

Para a identificações dos espécimes previamente coletados e inseridos na coleção do HUEFS (Sigla segundo Thiers 2016) foram utilizados métodos tradicionais em taxonomia. Além disso, foram utilizadas as imagens dos holótipos e isótipos das espécies encontradas na base de dados do SpeciesLink (http://splink.cria.org.br/) de modo a comparar e analisar os materiais depositados uma vez que existe uma alta diversidade morfológica em algumas espécies. Todos os materiais foram identificados e descritos com o auxilio de bibliografia especializada, tendo como ponto de partida os trabalhos de Renvoize (1984) e Zuloaga et al. (1993), que trazem revisões para as espécies da Bahia e do gênero como um todo, respectivamente. 


\section{RESULTADOS}

As buscas realizadas indicaram inicialmente a presença de 27 espécies de Dichanthelium no Brasil (Tab 1), uma a mais do que está referido na lista oficial da Flora (Viana \& Rodrigues 2016). Como não existe uma chave de identificação para as espécies desse gênero ocorrentes no Brasil e há grande complexidade morfológica envolvendo várias espécies ao longo da sua distribuição, assume-se aqui que é necessário investimentos futuros para se obter a confirmação sobre a quantidade e sobre a identidade das espécies desse gênero ocorrentes no Brasil.

Atualmente, a coleção do HUEFS conta com 97 espécimes de Dichanthelium coletados na Bahia, dos quais 63 pertencem a diferentes municípios da Chapada Diamantina. No total, foram analisados 58 espécimes confirmando as espécies D. adenoharchis (Zuloaga \& Morrone) Zuloaga, D. aequivaginatum (Swallen) Zuloaga, D. assurgens (Renvoize) Zuloaga, D. barbadense Salariato, Morrone \& Zuloaga, D. cabrerae (Zuloaga \& Morrone) Zuloaga, D. cumbucana (Renvoize) Zuloaga, D. pycnoclados (Tutin) Davidse, D. sciurotoides (Zuloaga \& Morrone) Davidse (Fig. 1) e D. stipiflorum (Renvoize) Zuloaga a partir da chave de identificação de Zuloaga et al. (1993) e análise do material tipo consultados em herbários virtuais. Acreditamos que outros táxons desse gênero provavelmente ocorrem na área, porém não se encaixam nas descrições das espécies conhecidas até o momento.

Além dessas, foram identificados seis morfotipos ocorrentes na área, que não se encaixam nas descrições das espécies conhecidas até o momento e nem entram nas chaves de identificação disponíveis. São eles Dichanthelium sp. 1, Dichanthelium sp. 2, Dichanthelium sp. 3, Dichanthelium sp. 4, Dichanthelium sp. 5 e Dichanthelium sp. 6, os quais devem ser posteriormente analisados em maiores detalhes, a fim de se confirmar se são novas espécies ou se representam apenas variações ainda não documentadas para as espécies conhecidas.
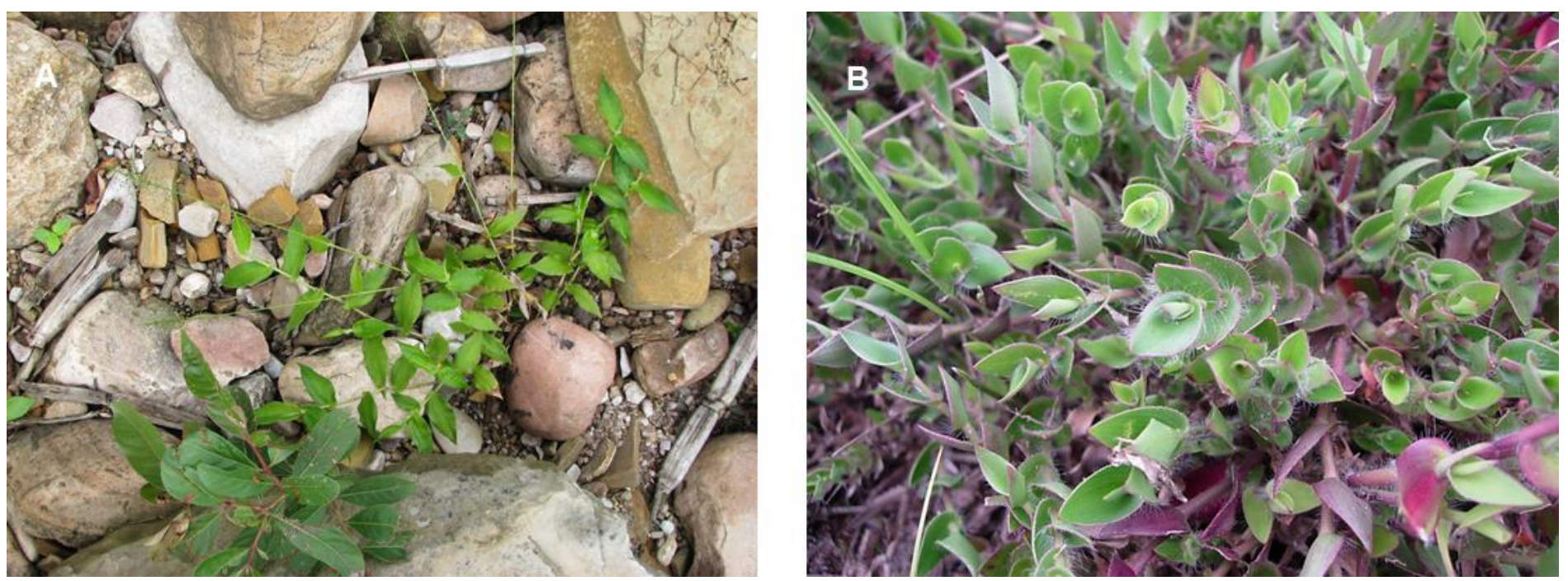

Figura 1 - A- Dichanthelium sciurotoides em campo. B- Dichanthelium sp 4 em campo.

\section{CONCLUSÃO}

A partir das analises realizadas foi possível confirmar a ocorrência de 09 espécies de Dichanthelium na Chapada Diamantina, além de pelo menos mais seis morfotipos que carecem de maiores estudos para definição de sua identidade taxonômica. Por isso é necessário garantir a continuidade dos estudos com esse gênero na região.

Além disso, foi possível realizar a revisão do material depositado em herbário, o que resultou na correção de identificações errôneas e consequentemente na reorganização da 
coleção. Outro ponto positivo trata-se do treinamento da bolsista enquanto taxonomista do gênero. A realização do projeto foi de grande importância para o aprendizado da mesma, além de abrir novos horizontes para estudo no gênero.

\section{REFERÊNCIAS BIBLIOGRÁFICAS}

Aliscioni, S.S.; Giussani, L.M.; Zuloaga, F.O. \&Kellogg, E.A. 2003. A molecular phylogeny of Panicum (Poaceae: Paniceae): Tests of monophyly and phylogenetic placement within the Panicoideae. American Journal of Botany.Vol. 90(5).796-821.

Brown, R. H. \& Smith, B. N. 1975.The genus Dichanthelium (Gramineae).Bulletin of the Torrey Botanical Club.Vol.102. 10-13.

Mori, S. A.; Silva, L.A.M.; Lisboa, G. \& Coradin, L. 1989. Manual de Manejo do Herbário Fanerogâmico. 2 ed. Centro de Pesquisas do Cacau, Ilhéus, Bahia.

Morrone, O. et al 2012. Phylogeny of the Paniceae (Poaceae: Panicoideae): integrating plastid DNA sequences and morphology into a new classification. Cladistics. Vol. 28. 333-356.

Renvoize, S.A. 1984. The grasses of Bahia. Royal Botanic Gardens, Kew.

Soreng, R.J. et al 2015. A World-wide Phylogenetic Classification of Poaceae (Gramineae). Journal of Systematics and Evolution.Vol.53.117-137.

Thiers, B. [continuously updated]. 2016. Index Herbariorum: A global directory of public herbaria and associated staff.New York BotanicalGarden's Virtual Herbarium. Disponível em: <http://sweetgum.nybg.org/science/ih/> Acesso em 20/03/2016.

Viana, P.L. \& Rodrigues, R.S. 2016. Dichanthelium in Lista de Espécies da Flora do Brasil. Jardim Botânico do Rio de Janeiro. Disponível em <http://floradobrasil.jbrj.gov.br/jabot/floradobrasil/FB13157>. Acesso em 20/03/2016.

Zuloaga, F. O.;Ellis, R. P.; Morrone, O. 1993.A revision of Panicum subg. Dichanthelium sect. Dichanthelium (Poaceae: Panicoideae:Paniceae) in Mesoamerica, the West Indies, and South America. Annals of the Missouri Botanical Garden. 80: 119-190. 